\title{
Preventing Alcohol-exposed Pregnancies
}

\author{
Mark B. Mengel, MD, MPH, H. Russell Searight, PhD, and Keely Cook, MPAS, PA-C
}

Fetal alcohol exposure affects approximately $1 \%$ to $3 \%$ of live births in the United States. Family physicians are in a unique position to reduce the incidence of alcohol-exposed pregnancy. Fetal alcohol exposure can be minimized through 2 general approaches: reducing alcohol consumption or increasing effective contraception among childbearing-aged women who engage in "at-risk" drinking and encouraging pregnant women to abstain from alcohol. Although no safe level of alcohol consumption during pregnancy is established, women who binge drink are more likely to deliver infants with physical and cognitive-developmental anomalies. Screening tools, such as quantity/frequency questions, the TWEAK and the T-ACE, developed specifically for prenatal care, are more useful with women than the CAGE and Michigan Alcohol Screening Test (MAST). Screening alone seems to reduce alcohol use among pregnant women. Brief interventions, including education about alcohol's effects on the developing fetus, are effective among women not responding to screening. Unfortunately, many barriers exist to effective implementation of alcohol-exposed pregnancy (AEP) prevention in the clinical setting. Designing effective office base systems so the entire burden of implementing AEP prevention activities does fall solely on the family physician is critical. (J Am Board Fam Med 2006;19:494-505.)

Effects of alcohol on the developing fetus are multifocal, incurable, pernicious, and extremely costly; however, these effects are eminently preventable. ${ }^{1-3}$ Despite the federal government warning that drinking alcohol during pregnancy is unsafe, ${ }^{4}$ and the fact that a safe threshold for alcohol consumption during pregnancy has not been demonstrated to exist either in human or animal studies, ${ }^{5-8}$ a substantial proportion of women selfreport that they continue to drink during pregnancy $(10.1 \%$ in 2002 , with $1.9 \%$ engaged in heavy drinking and $1.9 \%$ engaged in binge drink-

This article was externally peer-reviewed.

Submitted 19 October 2005; revised 17 March 2006; accepted 20 March 2006.

From the Department of Community and Family Medicine (MBM), St. Louis University; Behavioral Scientist, Forest Park Family Medicine Residency Training Program (HRS), St. Louis; Physician Assistant Education, Doisy College of Health Sciences (KC), St. Louis University, MO.

Funding: This publication was made possible through a cooperative agreement between the Association of Teachers of Preventive Medicine (ATPM) and the Centers for Disease Control and Prevention (CDC), award number U50/ CCU 300860 TS-0799; its contents are the responsibility of the authors and do not necessarily reflect the official views of the ATPM or the CDC.

Conflict of interest: none declared.

Corresponding author: Mark B. Mengel, MD, Department of Community and Family Medicine, St. Louis University School of Medicine, 1402 S. Grand Blvd., St. Louis, MO 63104 (E-mail: mengelmb@slu.edu). ing). ${ }^{9}$ Due to the continued high prevalence of drinking alcohol during pregnancy, the US Department of Health and Human Services has established a Healthy People 2010 goal to increase the number of pregnant women who report abstinence from alcohol use during the past month from a baseline rate in 1996 to 1997 of $86 \%$ to a 2010 target of $94 \% .^{10}$ In 2004, the US Preventive Services Task Forces recommended screening and counseling intervention in primary care settings to reduce alcohol misuse in adults, including pregnant women. ${ }^{11}$

Given the emphasis on prevention of adverse alcohol effects in the fetus through abstinence or drinking reduction in the mother, the term alcohol-exposed pregnancy (AEP) has been coined to help clinicians judge exposure status. AEP is defined as any pregnancy during which a woman drank any amount of alcohol at any time during her pregnancy. All fertile, sexually active, childbearingaged women are at risk for an AEP if they drink alcohol, are sexually active, and do not use contraception effectively. Preventing an AEP can be accomplished through 2 mechanisms: 1) engaging in abstinence from alcohol use before and during pregnancy, or 2) preventing pregnancy entirely by engaging in effective methods of contraception or abstaining from sexual activity. 
Family physicians can play a significant role in preventing AEP. Family physicians provide a significant portion of the primary care to childbearing-aged women in this country, and many family physicians continue to care for pregnant women. ${ }^{12,13}$ Prevention is recognized as one of the core tenets of family medicine, ${ }^{14}$ and family medicine physicians are generally among the best trained primary care physicians in dealing with issues of substance abuse and mental health. ${ }^{15}$ In surveys, many family physicians believe that dealing with substance use and abuse issues is within their purview as primary care physicians. ${ }^{16,17}$ By working to prevent AEP, family physicians can play a significant role in preventing the adverse effects of alcohol exposure, on the developing fetus.

\section{Potential Outcomes of Alcohol Use During Pregnancy}

Alcohol exposure during pregnancy has been shown to result in a spectrum of birth defects that can negatively affect a child's growth, cognition, physical appearance, and behavior over the lifespan. ${ }^{1,2,18,19}$ This spectrum of disorders is referred to as fetal alcohol spectrum disorders (FASD). FASD is not intended to be used as a clinical diagnosis, but rather as a descriptor to include the many adverse effects that alcohol can have on the developing fetus. Fetal alcohol syndrome (FAS) is the most serious disorder within this spectrum. ${ }^{1,2,18}$ Individuals affected with FAS have severe, permanent growth retardation, neurobehavioral abnormalities, and specific facial abnormalities. FAS is the leading cause of preventable birth defects and mental retardation in the United States. ${ }^{1}$

Unfortunately children with FAS represent only the tip of the iceberg of affected children, as numerous children exposed to alcohol in utero have significant physical or neurodevelopmental abnormalities without all the features of FAS. ${ }^{20}$ Alcoholrelated neurobehavioral disorder (ARND) refers to a constellation of neurobehavioral and central nervous system effects occurring in the absence of the characteristic facial and growth abnormalities associated with FAS. These abnormalities include: head circumference $\leq 10 \%$, learning disabilities, poor impulse control, seizures, deficits in higher level receptive and expressive language, and problems with mathematical skills, memory, attention, and judgment. Individuals that exhibit the typical FAS facies along with specific structural anomalies that are known to be associated with alcohol exposure such as low set ears, micrognathia, epicanthal folds, low nasal bridge, short upturned nose, strabismus, clinodactyly, "hockey stick" palmar crease, radioulnar synostosis, renal anomalies, and cardiac defects, but have normal growth and development, are classified as having alcohol-related birth defects (ARBD).

The prevalence of ARND and ARBD is estimated to be at least 4 times more common than FAS. ${ }^{1,21-23}$ Combining prevalence rates for FAS, ARND, and ARBD, $1 \%$ to $3 \%$ of all children born in the United States are affected by alcohol. This combined prevalence of FAS, ARND, and ARBD in the United States is probably underestimated because primary care providers and others who care for children do not routinely screen for FASD. ${ }^{24}$

\section{Alcohol Exposure Issues during Pregnancy}

Alcohol freely crosses the placenta and in most cases the blood alcohol level of the fetus is consistent with the blood alcohol level of the mother. ${ }^{1,25}$ Although all organ systems seem to be sensitive to alcohol's effects, the brain is particularly vulnerable. ${ }^{26}$ Alcohol's detrimental effects on the brain have been documented since the first report of FAS in the United States. ${ }^{1,4,17}$ Microcephaly; migration anomalies; agenesis or thinning of the corpus callosum and anterior commissures; cerebellar, brainstem, and basal ganglia anomalies; and neuroglial heterotropias have all been demonstrated. ${ }^{26-28} \mathrm{An}$ imal studies demonstrate that even low dose alcohol affects numerous aspects of brain structure and function, including neurogenesis, cell proliferation, and migration of cells, including connectivity, synaptosis, maturation, and apoptosis. ${ }^{27,28}$ On MRI studies, persons with FAS exhibit increased gray matter density, altered gray matter in portions of the temporal lobe, asymmetry, displacement, and reduction in the size of the corpus callosum, reduced brain growth in portions of the frontal lobe, and narrowing and reduction in the size of the temporoparietal regions. ${ }^{26}$ These regionally specific abnormalities in brain morphology suggest a causal relationship between the brain abnormalities consistently noted and the development of neurocognitive and behavioral effects typically seen in those prenatally exposed to alcohol. ${ }^{26,29}$ In addition, it was found that with higher levels of prenatal alcohol exposure, most morphologic findings were more pronounced in those individuals who exhib- 
ited FAS rather than those exhibiting the less severe phenotypes, ARND and ARBD. ${ }^{29,30}$

\section{Prevalence of Drinking in Childbearing-aged Women}

The Centers for Disease Control (CDC) monitors the prevalence of alcohol use among US women of childbearing age (18 to 44 years of age). In 2002, $54.9 \%$ of childbearing-aged women admitted to drinking. ${ }^{9}$ Unplanned pregnancies may occur when these women are drinking and do not use effective birth control. ${ }^{31} \mathrm{Up}$ to $50 \%$ of women who become pregnant will not realize that they are pregnant until after their 6th week of pregnancy, exposing their fetus to alcohol at a particularly vulnerable time. ${ }^{32}$ This fact is especially important because 1 in 8 women of childbearing age reports binge drinking in the past month. ${ }^{9}$ Binge drinking seems to be more harmful to the developing fetus than low-level daily drinking. ${ }^{1,33}$ It is thus imperative to take a preconceptual approach to advising women about alcohol intake. Any childbearing-aged women who are sexually active and not using effective methods of birth control should be advised to abstain from alcohol intake. In addition, when women drink, they are more likely to participate in risky behavior including having multiple partners and engaging in unprotected intercourse, increasing the likelihood of an AEP. ${ }^{34}$

\section{Risk Factors for an Alcobol-Exposed Pregnancy}

Many studies have identified factors that increase the risk of having an AEP, including advanced age, low socioeconomic status, and having a previous child with FAS (Table 1). Identification of these women with risk factors should cause the family physician to have a higher index of suspension for a potential AEP.

\section{Screening for Prenatal Alcobol Use}

Because some pregnant women continue to drink alcohol despite beverage warning labels, prenatal care should include repeated assessment of alcohol intake. Given the link between unprotected sex, unplanned pregnancy, and alcohol consumption, routine health maintenance visits for all women of childbearing age should address safe sex, alcohol use, and contraception. ${ }^{35-37}$

Although the Institute of Medicine and US Preventive Services Task Force advocates routine alcohol screening for pregnant women, recent esti-
Table 1. Risk Factors for an Alcohol-exposed Pregnancy

\begin{tabular}{lc}
\hline & References \\
\hline Age: $>30$ & 89,103 \\
Caucasian & 103 \\
Hx binge drinking or long history of & $91-93$ \\
$\quad$ drinking & \\
College educated & 103 \\
Low or high SES & 94,97 \\
Special Education populations & 90 \\
Poor Native Americans & 90 \\
Hx of physical/sexual abuse ever & 51 \\
Hx of physical abuse in past year & 103,105 \\
Heavy drinking by male partner or any & $95,97,98$ \\
$\quad$ family member & $94,95,99$ \\
Loss of children to foster/adoptive care & $92,93,96,104$ \\
Poly-drug use/cigarette smoking & 95 \\
Previous child with FAS & $51,100,104$ \\
Major depressive disorder & 51 \\
Post traumatic stress disorder & 89,98 \\
Unmarried & 101,102 \\
Early age of drinking onset & \\
\hline
\end{tabular}

Hx, history.

mates suggest that only approximately one third of pregnant women are assessed for alcohol use during routine prenatal care. ${ }^{11,38}$ When screening does occur, it is frequently confined to the initial prenatal visit instead of occurring at every prenatal visit. Even women who delay alcohol abstinence until the second trimester reduce the likelihood of an adverse birth outcome. ${ }^{39}$

Although physicians often order liver function tests, such as gamma glutamyltransferase (GGT) and aspartate aminotransferase (ALT), to obtain objective evidence of alcohol use disorders, they are less sensitive and specific than other assessment tools for identifying women at risk. ${ }^{40-42}$

\section{Screening Tools}

In assessing alcohol use in pregnant women, questionnaires, such as those listed in Table 2, may be particularly useful. The quantity/frequency questions developed by the National Institute on Alcohol Abuse provide information about current drinking patterns and may alert physicians to recent heavy or binge drinking. ${ }^{43}$ If clinicians detect heavy or binge drinking $(>7$ drinks/week or more than 3 drinks on any one occasion in females, respectively), follow-up questions about problems associated with alcohol use should be undertaken to 


\begin{tabular}{|c|c|c|c|c|c|}
\hline & Content & $\begin{array}{l}\text { Time } \\
\text { Required }\end{array}$ & $\begin{array}{l}\text { Scoring and Cut-Off } \\
\text { Score }\end{array}$ & Sensitivity & Specificity \\
\hline $\begin{array}{l}\text { Quantity/Frequency } \\
\text { Questions (3) }\end{array}$ & $\begin{array}{l}\text { Days per week of drinking } \\
\text { Average number of drinks per day } \\
\text { Maximum number of drinks } \\
\text { consumed in } 1 \text { day during the } \\
\text { past month }\end{array}$ & 2 minutes & $\begin{array}{l}>7 \text { drinks per week or }>3 \\
\text { drinks per day }\end{array}$ & N/A & N/A \\
\hline TWEAK $^{47}$ & $\begin{array}{l}\text { Tolerance: (a) How many drinks } \\
\text { does it take before you feel high } \\
\text { (the first effects of alcohol)? or } \\
\text { (b) How many drinks can you } \\
\text { hold? (How many drinks does it } \\
\text { take before the alcohol makes } \\
\text { you fall asleep or pass out? If } \\
\text { you never pass out, what is the } \\
\text { largest number of drinks you } \\
\text { have?) } \\
\text { Worried: Have your friends or } \\
\text { relatives worried about your } \\
\text { drinking in the past year? } \\
\text { Eye opener: Do you sometimes } \\
\text { take a drink in the morning } \\
\text { when you first get up? } \\
\text { Amnesia: Are there times when } \\
\text { you drink and afterwards can't } \\
\text { remember what you said or did? } \\
\text { K/Cut Down: Do you sometimes } \\
\text { feel the need to cut down on } \\
\text { your drinking? }\end{array}$ & 3 to 5 minutes & $\begin{array}{l}\text { Tolerance: (a) } 3 \text { drinks or } \\
\text { more or (b) } 5 \text { drinks or } \\
\text { more }+2 \text { points } \\
\text { Positive response to other } \\
\text { questions }=1 \text { point } \\
\text { each } \\
\text { Cut-off }=2 \text { points }\end{array}$ & $0.79-0.91$ & $0.77-0.83$ \\
\hline T-ACE ${ }^{48}$ & $\begin{array}{l}\text { Tolerance: How many drinks does } \\
\text { it take to make you feel high? } \\
\text { Annoyed: Have people ever } \\
\text { annoyed you by criticizing your } \\
\text { drinking? } \\
\text { Cut Down: Have you ever felt } \\
\text { that you needed to cut down on } \\
\text { your drinking? } \\
\text { Eye opener: Have you ever had a } \\
\text { drink first thing in the morning } \\
\text { to steady your nerves or get rid } \\
\text { of a hang over? }\end{array}$ & 2 to 3 minutes & $\begin{array}{l}\text { Tolerance: } 2 \text { points if } \\
\text { requires more than } 2 \\
\text { drinks } \\
\text { Other questions: } 1 \text { point } \\
\text { each } \\
\text { Cut off: } 2 \text { points }\end{array}$ & $0.70-0.89$ & $0.79-0.85$ \\
\hline
\end{tabular}

determine whether the patient meets DSM-IV criteria for alcohol dependence or abuse. Although quantity/frequency questions are easy to include in the clinical interview, this straightforward approach has limitations. On learning of their pregnancy, many women will temporarily reduce alcohol consumption. Information about prenatal drinking before pregnancy confirmation is likely to be more predictive of alcohol use over the entire prenatal period. ${ }^{44}$ Pregnant drinkers are likely to underreport their actual alcohol consumption with up to $40 \%$ of pregnant women underreporting their actual alcohol use. Women reporting consumption of as few as 1.3 drinks/week are, in reality, probably consuming greater quantities, placing them at risk for ARBD. ${ }^{45,46}$

Unfortunately, the CAGE questions and the Michigan Alcohol Screening Test (MAST) have poor specificity in prenatal populations. ${ }^{43,44}$ Both methods were developed primarily in males and emphasize social consequences of heavy, long-term alcohol use. In addition to inquiring about recent quantity and frequency of alcohol use, 2 screening measures developed for pregnant women, the $\mathrm{T}$ ACE and the TWEAK, have been found to be particularly sensitive and specific (see Table 2).

The TWEAK and T-ACE are often seen as superior to direct inquiry about alcohol use because these instruments focus on indirect effects of drinking and may reduce patients' defensiveness. ${ }^{8}$ Administered as part of the clinical interview, the TWEAK includes 3 questions adapted from the CAGE and MAST found to identify obstetric patients using alcohol. The TWEAK adds questions about tolerance to detect at-risk drinking specifically among pregnant women. Because tolerance to 
alcohol may develop fairly rapidly, this addition may improve detection of pregnant drinkers. ${ }^{47}$

The T-ACE was developed specifically for obstetric-gynecologic settings. ${ }^{48}$ The scale features items from the CAGE along with a tolerance question. Because most patients do not know socially desirable responses to the tolerance question, this dimension, given double weight in the T-ACE, may be particularly useful. Two slightly different questions have been used to assess alcohol tolerance: "How many drinks does it take to get you high?" and "How many drinks can you hold?" The "hold" question was found to be more sensitive but less specific than the "high" question. Because these measures are for initial screening, the "hold" version is preferred. ${ }^{48}$ By asking about alcohol problems indirectly, the tendency to deny or underreport alcohol use by pregnant drinkers may be circumvented.

The Alcohol Use Disorder Identification Test (AUDIT) is a 10-item tool designed to detect early stages of problem drinking. ${ }^{49}$ In comparison to other measures that mix items dealing with past and present drinking, the AUDIT focuses on drinking patterns during the past year. An advantage of the AUDIT, in addition to its broader coverage, is that patients complete the scale on their own, and the physician can use the completed form to guide follow-up questions.

\section{Clinical Issues with Screening Measures}

Because of social desirability, some pregnant women, particularly heavy drinkers, may be more likely to reliably report their actual alcohol use in a computerized or "pencil and paper" task rather than through a face-to-face interview. ${ }^{50}$

Because of concerns about patients' minimization of alcohol use on quantity/frequency questions, some physicians also interview collateral informants such as a spouse. Although nearly all research to date has focused on male drinkers and female collateral informants, available studies suggest that these informants also under-report the patient's alcohol consumption. ${ }^{51}$

These screening tools do not replace careful clinical interviewing. A positive response to these scales is not diagnostically specific and only indicates that a woman is at-risk for alcohol problems. Last, responses to these measures may be influenced by ethnicity. For example, White women, compared with African-American women, are much more likely to report morning drinking. In addition, White women report a much greater tolerance for alcohol and typically indicate that they can "hold" a larger number of drinks, requiring more drinks to feel "high." 52

\section{Overview of Brief Intervention in Primary Care}

Brief physician intervention successfully reduces alcohol use among primary care patients among heavy and binge drinkers. ${ }^{53,54}$ The content of brief intervention typically includes advice, feedback, goal setting, and additional contacts as necessary. Whitlock et al labels these elements as the 5 "A"s: assess, advise, agree, assist, and arrange. ${ }^{54}$

Brief interventions for alcohol abuse have been classified into 3 types: 1 ) very brief (one 5 -minute session); 2) brief (one session up to 15 minutes duration); 3) multicontact brief sessions (an initial session of up to 15 minutes followed by several time-limited contacts, either by phone or in the clinic). ${ }^{53}$ These brief treatments are often equally effective as longer-term therapy. ${ }^{54}$ When compared with "usual" care, multiple contact brief interventions lead to $10 \%$ to $19 \%$ of patients changing to recommended or safe drinking levels. The overall absolute risk reduction associated with brief treatments is $10.5 \% .{ }^{53}$ Multicontact interventions are associated with greater risk reduction than single contact treatment. Because pregnant women are scheduled for multiple, closely spaced office visits, brief multicontact alcohol counseling can be readily incorporated into prenatal care. In addition, there are suggestions that these brief treatments may be more effective with women than men. Fleming et al found that 1 year after a brief intervention, women had reduced their weekly alcohol consumption by $47 \%$ compared with $37 \%$ for men. ${ }^{53}$ Binge drinking was also reduced to a greater extent among women compared with men receiving a brief intervention.

\section{Brief Intervention among Pregnant Women}

Assessment alone seems to reduce alcohol consumption. Fleming et al's control group, which was asked about their alcohol use at 4 different time points throughout the year, reduced consumption by $20 \% .^{53}$ Among pregnant women, formal screening with tools such as the T-ACE alone, reduces prenatal consumption. ${ }^{48}$ Physician advice or written educational information improves patients' knowledge of the risks of drinking during pregnan- 
cy. ${ }^{55-57}$ Providing information alone may reduce the risk of an alcohol-exposed pregnancy through reduced consumption or increased use of effective contraception. Information's beneficial effects on reducing risk may persist for up to 9 months. ${ }^{57} \mathrm{It}$ is likely that when coupled with education and advice, assessment may be adequate to prevent further drinking during pregnancy among most patients. ${ }^{46}$

After completing an initial screening and providing general information about the risks for drinking during pregnancy, at-risk patients should receive individualized feedback. The physician explains how the patient's drinking compares with other pregnant women or those of childbearing age. If possible, the physician then describes risks specific to the patient. Next, the physician and patient establish drinking goals, complete cessation of drinking during pregnancy is recommended. After establishing drinking goals; the patient is encouraged to "brainstorm" environmental triggers (eg, socializing with friends who are drinking) and develop behavioral alternatives for these at-risk periods. Counseling is augmented by written patient educational material such as self-paced workbooks. ${ }^{53}$ Keeping a drinking diary, recording the number of alcoholic drinks, and drinking circumstances each day, is often recommended.

Motivational interviewing (MI), a counseling model developed for health risk behavior, has also demonstrated success in reducing prenatal alcohol use-particularly among heavier drinkers. ${ }^{58,59} \mathrm{MI}$, combining education and reflective questions, in a supportive context, has also been effective in increasing contraceptive use in female drinkers who could become pregnant. ${ }^{59}$

\section{Brief Intervention: Evidence for Effectiveness in Reducing AEP}

Although brief alcohol intervention has a reasonable evidence basis, there are only limited investigations involving pregnant patients. The Trial for Early Alcohol Treatment (Project TrEAT) involved four 2- to 15-minute office counseling sessions and a self-paced workbook directed toward women of childbearing age. ${ }^{60}$ The intervention led to a $48 \%$ reduction in average alcohol intake with $25 \%$ fewer women engaging in binge drinking. Although Project TrEAT's benefits were still pronounced at 48 months, the largest decline in alcohol use occurred within 6 months after the intervention. ${ }^{60}$
A more intensive intervention, Project CHOICES, targeted women at-risk for an alcoholexposed pregnancy. ${ }^{61}$ Risk status included a week of low level daily drinking and/or binge episode in the past 3 months, recent sexual activity, and no or ineffective contraception. Women participated in 4 motivational interviewing sessions and received individualized information about their risk of an AEP. Risk reduction included decreased alcohol use $(18 \%)$, effective contraception (34\%), or both (48\%) with $68 \%$ of the participants reducing their risk of an AEP. In a further analysis comparing only education about drinking during pregnancy with education plus counseling, 54.8\% receiving education alone reduced their risk of an AEP with a $68.9 \%$ risk reduction for education with added counseling. ${ }^{58}$

Chang et al provided brief treatment to women in the 16th week of pregnancy who screened positive on the T-ACE and examined motivational factors associated with risk reduction. ${ }^{48}$ The intervention included a review of the patient's general health status, and lifestyle changes along with education about alcohol abstinence, goal-setting, brainstorming, and an alcohol prevention manual for individual use. ${ }^{62}$ Women articulating specific concerns about preventing FAS rather than general statements about their baby's health, were more likely to reduce alcohol consumption. Women who had been drinking in the previous 6 months, but not in the 90 days before the intervention, were also more successful in reducing alcohol consumption. $^{38,62}$ A detailed assessment, alone, was found to be as effective as an assessment followed by brief intervention in reducing alcohol consumption during pregnancy. However, brief intervention was more effective with the subgroup of heavier drinkers. This benefit, for heavier drinkers, was further augmented when the patient's partner was involved in brief treatment. ${ }^{63}$

Women drinking at light to moderate levels seem to benefit most from brief treatment. ${ }^{64} \mathrm{Mo}-$ tivational factors, including a patient's belief that they can successfully stop drinking, is strongly associated with successful outcomes. For highly motivated patients, self-help manuals alone have been found to produce significant reductions in alcohol use. ${ }^{65}$ Whereas research is limited, brief physician counseling, which may include concerned family members, can increase the likelihood that a patient will enter an intensive substance abuse treatment 
Table 3. Barriers to Providing Screening, Assessment, Brief Intervention, and Referral Services to Prevent Alcohol-exposed Pregnancies

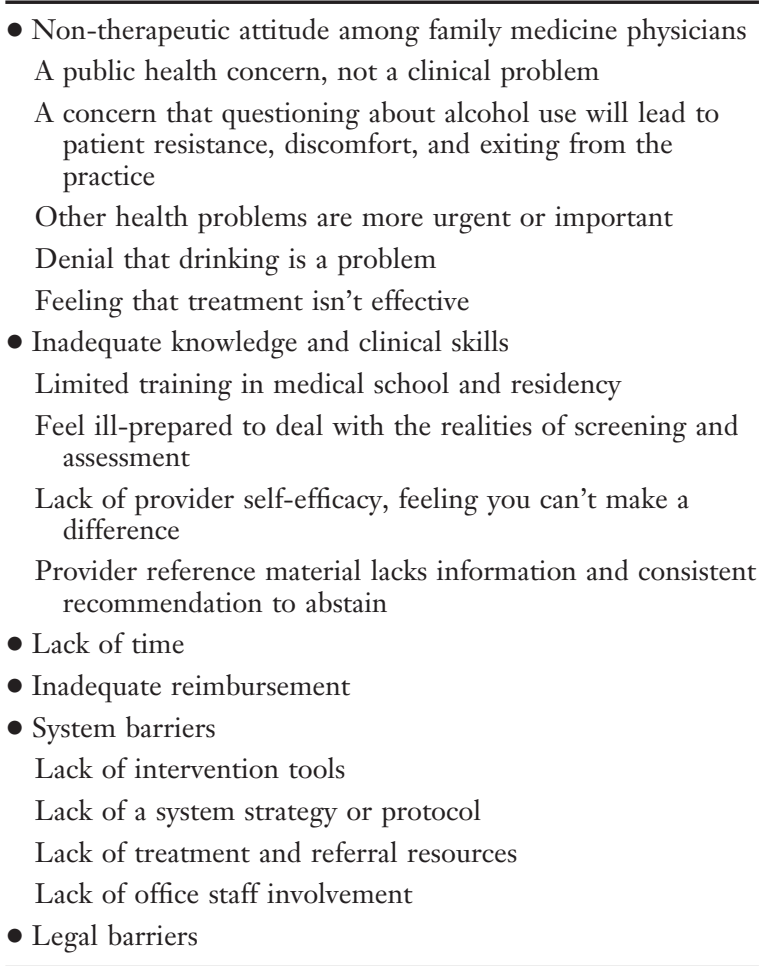

program, ${ }^{66,67}$ although many clinicians would refer a patient who meets criteria for alcohol abuse or dependence to a substance abuse counselor immediately rather than performing a brief intervention first.

\section{Barriers to AEP Prevention in Clinical Practice}

Given the evidence that screening, assessment, education, and brief interventions directed at alcohol use can identify women with alcohol disorders, these practices should be a standard part of a family physician's clinical practice. However, evidence from surveys of family physicians and other health care professionals suggests many barriers to the routine integration of these practices into clinical practice (see Table 3). ${ }^{14-16,68-75}$ Studies suggest that few family physicians provide all these services, and fewer patients report receiving them. ${ }^{75-78}$

Unfortunately, simple educational efforts, training and encouraging family physicians to include these services in their clinical practice, will probably not be enough to ensure integration of these skills into clinical practice. Studies that not only teach these skills, but do so from a systems perspec-
Table 4. Common Myths Regarding Alcohol Use during Pregnancy

1. Less than 1 drink per day in pregnancy is okay.

2. Drinking late in pregnancy is okay and makes labor easier.

3. Beer and wine are not alcohol, and thus are not a problem.

4. If I drank and have one child without FAS, I can drink and I won't have another child with FAS.

5. If FAS doesn't run in my family, my child won't get FAS.

6. FAS is curable if diagnosed early.

tive, suggest success might be achieved with this new approach. ${ }^{79-82}$ Babor and colleagues trained 44 physicians and 41 clinical non-physicians in 10 practices across the country using a 3-hour training module aimed at assisting implementation of alcohol screening and brief intervention services in the primary care setting. ${ }^{82}$ The proportion of at-risk drinkers, 3 months after the intervention, in which physicians screened for alcohol use and provided intervention was greater in physicians who received the training than those who did not $(47 \%$ versus $22 \%)$. Actually helping physicians deal with systems barriers in their office and constructing an office support system that facilitated these activities was the key to the success of this educational intervention.

Several patient barriers to preventing AEP also exist, such as patient denial that a problem exists. Surveys have documented lack of knowledge among women, particularly in high-risk groups, regarding the effects of alcohol on the fetus and the importance of abstinence from alcohol during pregnancy. ${ }^{83-87}$ Many women believe myths about alcohol use during pregnancy that produce the belief that they are not at risk for an AEP (see Table 4).

Besides accurate knowledge, changing drinking patterns or abstaining from alcohol when pregnant requires behavioral change. Behavioral change requires the patient's time, attention, motivation, and often a helpful, supportive context that facilitates the efforts of the patient to make that change. The patient may not be willing to undergo a behavioral change process due to the time and effort required, confronting resistance from an unsupportive context (such as family and friends who drink freely), or feeling that they will fail (lack of self-efficacy). Further complicating matters are the widespread prodrinking messages childbearing-aged women receive from the media and the popular culture. ${ }^{87}$

To integrate preventing AEP within their office practice, family physicians can take several steps to 


\begin{tabular}{|c|c|}
\hline Activity & Strategies \\
\hline Screening & $\begin{array}{l}\text { Include alcohol screening questions on initial patient questionnaires } \\
\text { or instruct medical assistants to assess alcohol use while assessing } \\
\text { vital signs during initial patient intake. }\end{array}$ \\
\hline Assessment & $\begin{array}{l}\text { Construct a questionnaire or checklist for the nurse to perform the } \\
\text { assessment if screening is positive prior to the physician seeing the } \\
\text { patient or construct a checklist that the physician can use if initial } \\
\text { screening questions are positive while visiting with the patient in } \\
\text { the examination room }\end{array}$ \\
\hline Education (on alcohol and contraceptive practices) & $\begin{array}{l}\text { The clinic nurse can provide alcohol-exposed pregnancy (AEP) } \\
\text { prevention education during preconception counseling visits, } \\
\text { contraceptive initiation visits, or pregnancy education visits. Posters } \\
\text { and brochures on AEP can be placed in waiting rooms and } \\
\text { examination rooms. }\end{array}$ \\
\hline Brief interventions & $\begin{array}{l}\text { Nurses can be trained to conduct brief interventions and follow-up } \\
\text { visits can be conducted by telephone. Brief intervention materials } \\
\text { can be kept in the examination rooms for physicians to use. }\end{array}$ \\
\hline
\end{tabular}

insure that the burden of carrying out AEP prevention activities does not solely fall on themselves. Table 5 describes strategies for organizing an office practice to facilitate AEP prevention, including using already existing office procedures, such as including quantity and frequency questions on an initial new patient office questionnaire, using office personnel to conduct further assessment and brief interventions, and conducting some of the follow-up visits for a brief intervention over the phone. Obviously, AEP prevention activities can also be integrated within existing alcohol screening, assessment, and intervention activities for all patients.

\section{Conclusion}

Current evidence suggests that if family medicine physicians engage in routine screening, assessment, education, and intervention in women of childbearing age regarding their use of alcohol that the risk of AEP will be decreased (Table 6). Alcohol is a toxin that can result in a range of abnormalities in children; perhaps, the most devastating of which are the neurobehavioral and central nervous system effects. Although profoundly disturbing in their on way, these initial neurobehavioral and cognitive affects result in secondary disabilities in the teenage years that often preclude these individuals from reaching independence as adults. ${ }^{88}$ Because these FASD do not occur in the absence of prenatal alcohol exposure and because there is no known cure once they have occurred, preventing an AEP is the most logical intervention strategy for this problem at this time.

Integrating these intervention techniques within family medicine practice will not be easy. Current research suggests that the involvement of the staff and the design of effective office systems could take most of the burden of performing these activities off the family physician and might be the most

Table 6. Strength of Evidence: Preventing Alcohol-exposed Pregnancies Summary Statement of Evidence

3. Approximately one-half of all childbearing-aged women in the United States drink alcohol

4. Approximately $10 \%$ of all women drink alcohol while pregnant

5. Although binge drinking (more than 3 drinks on one occasion) demonstrates the strongest adverse effect on the

6. With prenatal patients, the T-ACE and TWEAK are more effective screening measures than the CAGE.

7. Screening for alcohol use in routine office visits will decrease patients' alcohol consumption.

8. Brief physician education and intervention about alcohol use in childbearing-aged women will reduce alcohol use, 
effective way of integrating these practices within family practice.

Clearly further translational research is needed to determine the best ways to integrate these practices within the busy family medicine office setting. Practice-based research networks would be an ideal laboratory for carrying out this translational research. Such research should focus on the effectiveness of these practices in the family medicine office setting and determine their impact on reducing alcohol-exposed pregnancy risk and decreasing the prevalence of FASD.

\section{References}

1. Stratton K, Howe C, Battaglia F, editors. Fetal Alcohol Syndrome: Diagnosis, Epidemiology, Prevention and Treatment. Washington (DC): National Academy Press; 1996.

2. Sokol RJ, Delaney-Black V, Nordstrom B. Fetal alcohol spectrum disorder. JAMA 2003;290: 2996-9.

3. Wattendorf DJ, Muenke M. Fetal alcohol spectrum disorder. Am Fam Physician 2005;72:279-82.

4. Surgeon General's Advisory on Alcohol Use in Pregnancy. News Release. U.S. Department of Health and Human Services, February 21, 2005. Available from: www.surgeongeneral.gov/pressreleases/sg02222005. html (accessed Aug 18, 2005).

5. Lundsberg LS, Bracken MB, Saftlas AF. Low-tomoderate gestational alcohol use and intrauterine growth retardation, low birth-weight, and preterm delivery. Ann Epidemiol 1997;7:498-508.

6. Jacobson JL, Jacobson SW. Prenatal alcohol exposure and neurobehavioral development: where is the threshold? Alcohol Clin Exp Res 1994;18:30-6.

7. Shaw GM, Lammer EJ. Maternal periconceptional alcohol consumption and risk for orofacial clefts. J Pediat 1999;134:298-303.

8. Sood B, Delaney-Black V, Covington C, et al. Parental alcohol exposure and childhood behavior at 6 to 7 years. I: Dose-response effect. Pediatrics 2001; 108:E34.

9. Tsai J, Floyd RL. Alcohol consumption among women who are pregnant or who might become pregnant-United States 2002. MMWR Moeb Mortal Wkly Rep 2004;53:1178-81.

10. U.S. Department of Health and Human Services. Healthy People 2010. 2nd Ed. Vol 2. Washington (DC): U.S. Government Printing Office, Nov 2000, p. 16-45.

11. U.S. Preventive Service Task Force. Screening for Alcohol Misuse, April 2004. Available from: www.ahrq.gov/clinic/uspstf/uspsdrin.htm (accessed March 1, 2006).

12. 2005 Facts about Family Medicine, Table 27. Number of visits by sex and age of patient to all physicians and selected specialty, United States, 2003. Available from: www.aafp.org/x782.xml (accessed Aug 18, 2005).

13. Cohen D, Guirguis-Blake J, Jack B, et al. The case of the State of Maine: family physicians make a substantial contribution to maternity care Am Fam Physician 2003;68:425.

14. Fryor GE, Dovey SM, Green LA. The importance of primary care physicians as the usual source of health in the acheivement of preventive goals. Am Fam Physician 2000;62:1968.

15. National Center on Addiction and Substance Abuse (CASA). Missed opportunity: national survey of primary care physicians and patients on substance abuse. New York: CASA; April 2000. p 5-17.

16. Anderson P. Managing alcohol problems in general practice. Br Med J 1985;29:1873-5.

17. Rush BP, Bass M, Stewart M, et al. Detection, prevention and management of patient's alcohol problems by Canadian family physicians. Can Fam Physician 1994;40:1557-66.

18. Jones KL, Smith DW. Recognition of the fetal alcohol syndrome in early infancy. Lancet 1973;2: 999-1001.

19. Centers for Disease Control. National Task Force on Fetal Alcohol Syndrome and Fetal Alcohol Effect. Fetal alcohol syndrome: guidelines for referral and diagnosis. Atlanta (GA): U.S. Department of Health and Human Services; 2004.

20. Mattson SN, Riley EP, Gramling L, et al. Heavy prenatal alcohol exposure with or without physical features of fetal alcohol syndrome lead to IQ deficits. J Pediatr 1997;131:718.

21. Hoyme HE, May PA, Kalberg WO, et al. A practical clinical approach to diagnosis of fetal alcohol spectrum disorders: clarification of the 1996 Institute of Medicine criteria. Pediatrics 2005;115:39-47.

22. May PA, Gossage JP, White-Country M, et al. Alcohol consumption and other maternal risk factors for fetal alcohol syndrome among three distinct samples of women before, during and after pregnancy: the risk is relative. Am J Med Genet 2004; 127C(Vol 1):10-20.

23. May PA, Gossage JP. Estimating the prevalence of fetal alcohol syndrome. Alcohol Res Health 2001; 2:159-67.

24. Graham JM Jr., Hanson JW, Darby BL, et al. Independent dysmorphology evaluations at birth and 4 years of age for children exposed to varying amounts of alcohol in utero. Pediatrics 1998;81: 772.

25. Little BB, Vanbeveren TT. Placental transfer of selected substances of abuse. Semin Perinatol 1996; 20:147-53.

26. Riley EP, McGee CL, Sowell ER. Teratogenic effects of alcohol: a decade of brain imaging. Am J Med Genet 2004;127C:35-41.

27. Mattson SN, Riley EP. Brain anomalies in fetal 
alcohol syndrome. In: Able EL, editor. Fetal alcohol syndrome: from mechanism to prevention. Boca Raton (FL): CRC Press; 1996. p. 51-68.

28. Clarren KS. Neuropathology in fetal alcohol syndrome. In West JR, editor. Alcohol and Brain Development. New York: Oxford University Press; 1986. p. $158-66$.

29. Mattson SN, Fennam-Notestine C, Gamst A, et al. Fetal alcohol syndrome: a case report of neuropsychological, MRI and EEG assessment of two children. Alcohol Clin Exp Res 1992;16:1001-3.

30. Archibald SL, Fennema-Notestine C, Gamst AC, et al. Brain dysmorphology in individuals with severe prenatal alcohol exposure. Dev Med Child Neurol 2001;43:148-54.

31. Project Choices Research Group. Alcohol-exposed pregnancy: characteristics associated with risk. Am J Prev Med 2002;23:166-73.

32. Floyd RL, Decoule P, Hungerford DW. Alcohol use prior to pregnancy recognition. Am J Prev Med 1999;17:101-107.

33. Maier SE, West JR. Drinking patterns and alcoholrelated birth defects. Alcohol Res Health 2001;25: $168-74$.

34. Wechesler H, Davenport A, Dowdell G, Moeykens B, Castillo S. Health and behavior consequences of binge drinking in college: a national survey of students in 140 campuses. JAMA 1994:272:1672-7.

35. Bertrand J, Floyd RL, Weber MK, et al. National Task Force on FAS/FAE. Fetal alcohol syndrome: guidelines for referral and diagnosis. Atlanta (GA): Centers for Diseases Control and Prevention; 2004. p. 28.

36. Institute of Medicine. Broadening the base of treatment for alcohol problems. Washington (DC): National Academy Press; 1990.

37. Naimi TS, Lipscomb AL, Brewer RD, Gilbert BC. Binge drinking in the preconception period and the risk of unintended pregnancy: implications for women and their children. Pediatrics 2003;111: 1136-41.

38. Chang G, Goetz MA, Wilkins-Haug L, Berman S. A brief intervention for prenatal alcohol use: an in-depth look. J Substance Abuse Treatment 2000; 18:365-9.

39. Autti-Ramo L, Korkman M, Hilakivi-Clark L, Lehtonen M, Halmesmaki E, Granstrom ML. Mental development of 2 year old children exposed to alcohol in utero. J Pediatr 1992;120:740-48.

40. Allen J, Litten RZ, Fertig JB, Sillanaukee P. Carbohydrate-deficient transferring, gamma-glutamyltransferase, and macrocytic volume as biomarkers of alcohol problems in women. Alcohol Clin Exp Res 2000;24:492-6.

41. Substance Abuse and Mental Health Services Administration. A guide to substance abuse services for primary care clinicians. Treatment improvement protocol (TIP) series \#24. Washington (DC):
US Department of Health and Human Services Government Printing Office; 1997.

42. Bearer CF. Markers to detect drinking during pregnancy. Alcohol Res Health 2001;25:210-8.

43. National Institute on Alcohol Abuse and Alcoholism. The physician's guide to helping patients with alcohol problems. National Institutes of Health Publication No. 95-3769. Rockville (MD): Department of Health and Human Services; 1995.

44. Chang G. Alcohol-screening instruments for pregnant women. Alcohol Res Health 2001;25:204-9.

45. Ernhart CB, Morrow-Tlucak M, Sokol RJ, Martier S. Underreporting of alcohol use in pregnancy. Alcohol Clin Exp Res 1998;12:506-11.

46. Morrow-Tlucak M, Ernhart CB, Sokol RJ, Martier $\mathrm{S}$, Ager J. Underreporting of alcohol use in pregnancy: relationship to alcohol problem history. Alcohol Clin Exp Res 1989;13:399-401.

47. Russel M. New assessment tools for risk drinking during pregnancy. Alcohol Health Res World 1994;18:55-61.

48. Sokol RJ, Martier SS, Ager JW. The T-ACE questions: practical prenatal detection of risk-drinking. Am J Obstet Gynecol 1989;160:863-8.

49. Saunders JB, Aasland OG, Babor TF, DeLa Fuente JR, Grant M. Development of the Alcohol Use Disorders Identification Test (AUDIT): WHO collaborative project on early detection of persons with harmful alcohol consumption-II. Addiction 1993;88:791-804.

50. Thornberry J, Bhaskar B, Krukwitch CJ, et al. Audio computerized self-report interview use in prenatal clinics. CIN: Computers, Informatics, Nursing 2002;20:46-62.

51. Svikis DS, Reid-Guinones K. Screening and prevention of alcohol and drug use disorders in women. Obstet Gynecol Clin N Am 2003;30:44768.

52. Russell M, Skinner JB. Early measures of maternal alcohol misuse as predictors of adverse pregnancy outcomes. Alcohol Clin Exp Res 1988;12:824-30.

53. Fleming MF, Barry KL, Manwell LB, Johnson K, London R. Brief physician advice for problem alcohol drinkers. A randomized controlled trial in community-based primary care practices. JAMA 1997;277:1039-45.

54. Whitlock EP, Polen MR, Green C, Orleans CT, Klein J. Behavioral counseling interventions in primary care to reduce risky, harmful alcohol use by adults: a summary of the evidence for the U.S. Preventive Services Task Force. Ann Intern Med 2004;140:558-69.

55. Project MATCH Research Group. Matching alcoholism treatments to client heterogeneity: Project MATCH three-year drinking outcomes. Alcohol Clin Exp Res 1998;22:1300-11.

56. Chang G, Wilkins-Haug L, Berman S, Goetz MA, 
Behr H, Hiley A. Alcohol use: improving identification. Obstet Gynecol 1998;91:892-8.

57. Waterson EJ, Murray-Lyon IA. Preventing fetal alcohol effects: a trial of three methods of giving information in the antenatal clinic. Health Educ Res 1990;5:53-61.

58. Floyd L. Presentation at the National Task Force on FAS/FAE. June 15, 2005. Atlanta (GA): U.S. Public Health Service.

59. Handmaker NS, Wilbourne P. Motivational interventions in prenatal clinics. Alcohol Res Health 2001;25:219-29.

60. Manwell LG, Fleming MF, Mundt MP. Treatment of problem alcohol use in women of childbearing age: results of a brief intervention trial. Alcohol Clin Exp Res 2000;24:1519-24.

61. The Project Choices Intervention Research Group. Reducing the risk of alcohol-exposed pregnancies: a study of a motivational intervention in community settings. Pediatrics 2003;111:1131-5.

62. Chang G, Wilkins-Haug L, Berman S, Goetz M. A brief intervention for alcohol use in pregnancy: A randomized trial. Addiction 1999;94:1499-508.

63. Chang G, McNamara TK, Orav J, Kolby D, Lavigne A, Wilkins-Huang L. Brief intervention for prenatal alcohol use: a randomized trial. Obstet Gynecol 2005;105:991-8.

64. Hankin JR. Fetal alcohol syndrome prevention research. Alcohol Res Health 2002;26:58-65.

65. Spivak K, Sanchez-Craig M, Davila R. Assisting problem drinkers to change on their own: effect of specific and nonspecific advice. Addiction 1994;89: $1135-42$.

66. Chafetz ME, Blane HT, Abram HS, et al. Establishing treatment relations with alcoholics. J Nerv Ment Dis 1962;134:395-409.

67. Edwards ME, Steinglass P. Family therapy treatment outcomes for alcoholism. J Marital Fam Ther 1995;21:475-510.

68. Bradley K, Curry S, Koepsell T, et al. Primary and secondary prevention of alcohol problems: U.S. internist attitudes and practices. J Gen Intern Med 1995;10:67-72.

69. Brown RL. Evaluation of a continuing medical education program for primary care physicians on the management of alcoholism. J Med Ed 1988;63:482-4.

70. Fleming MF, Manwell LB, Kraus M, et al. Who teaches residents about the prevention and treatment of substance use disorders? A national survey. J Fam Pract 1999;48:726-9.

71. Haack M, Adger H, editors. Strategic plan for interdisciplinary faculty development: arming the nation's health professional workforce for a new approach to substance use disorders. Substance Abuse 2002;23(Suppl):1-345.

72. Yarnall KS, Pollak KI, Ostbye T, Krause KM,
Michener JL. Primary care: is there enough time for prevention? Am J Publ Health 2003;93:635-41.

73. Aira M, Kauhanen J, Larivaara P, Rautio P. Factors influencing inquiry about patients' alcohol consumption by primary healthcare physicians: qualitative semi-structured interview study. Fam Pract 2003;20:270-5.

74. Rush BR, Powell LY, Crowe TG, et al. Early intervention for alcohol use: family physician's motivations and perceived barriers. Can Med Assoc J 1995;152:863-9.

75. Barry KL, Blow FC, Willenbring M, et al. Use of alcohol screening and brief interventions in primary care settings: implementation and barriers. Substance Abuse 2004;25:27-36.

76. Friedmann PD, McCullough D, Chin MH, et al. Screening and intervention for alcohol problems: a national survey of primary care physicians and psychiatrists. J Gen Intern Med 2000;15:84-91.

77. Arndt S, Schultz SK, Turrey C, et al. Screening for alcoholism in the primary care setting: are we talking to the right people J Fam Pract 2002;51:41-6.

78. Weisner C, Matzger H. Missed opportunities in addressing drinking behavior in medical and mental health services. Alcohol Clin Exp Res 2003;27: 1132-41.

79. Ockene J, Adams A, Hurley T, Wheeler E, Hebert J. Brief physician- and nurse practitioner-delivered counseling for high-risk drinkers. Arch Intern Med 1999;159:2198-205.

80. Adams A, Ockene J, Wheeler E, Hurley T. Alcohol counseling: physicians will do it. J Gen Intern Med 1998;13:692-8.

81. Saitz R, Horton NJ, Sullivan LM, et al. Addressing alcohol problems in primary care: a clustered randomized, controlled trial of a system intervention. Ann Intern Med 2003;138:372-82.

82. Babor TF, Higgins-Biddle JC, Higgins PS, et al. Training medical providers to conduct alcohol screening and brief interventions. Substance Abuse 2004;25:17-26.

83. Testa M, Reifman A. Individual differences in perceived riskiness of drinking in pregnancy: antecedents and consequences. J Stud Alcohol 1996;57: 360-7.

84. Kesmodel U, Schioler-Kesmodel P. Drinking during pregnancy: attitudes and knowledge among pregnant Danish women, 1998. Alcohol Clin Exp Res 2002;26:1553-60.

85. Cornelius MD, Lebow HA, Day NL. Attitudes and knowledge about drinking: relationships with drinking behavior among pregnant teenagers. J Drug Educ 1997;27:231-43.

86. Kaskutas LA. Understanding drinking during pregnancy among urban American Indians and African Americans: health messages, risk beliefs, and how we measure consumption. Alcohol Clin Exp Res 2000;24:1241-50. 
87. The Center on Alcohol Marketing and Youth. Exposure of African-American youth to alcohol advertising. Washington (DC): Georgetown University; 2003. Available from: http://camy.org/research/ afam0603/.

88. Streissguth AP, Barr HM, Kogan J, et al. Understanding the occurrence of secondary disabilities in clients with fetal alcohol syndrome (FAS) and fetal alcohol effects (FAE). Atlanta (GA): CDC, 1996.

89. Sidhu JS, Floyd, RL. Alcohol use among women of childbearing age-United States 1991-1999. MMWR Morb Mortal Wkly Rep 2002;51:273-6.

90. Abel EL. An update on incidence of FAS: FAS is not an equal opportunity birth defect. Neurotoxicol Teratol 1995;17:437-43.

91. Chang G, Behn H, Goetx MA, Hiley A, Bigby J. Women and alcohol abuse in primary care: identification and intervention. Am J Addict 1997;6:18392.

92. Day NL, Cottreau CM, Richardson GA. The epidemiology of alcohol, marijuana, and cocaine use among women of childbearing age and pregnant women. Clin Obstet Gynecol 1993;36:232-45.

93. Godel JC, Pabst JF, Hodges PE, Johnson KE, Froese GJ, Joffres MR. Smoking and caffeine and alcohol intake during pregnancy in northern populations: effect of fetal growth. Can Med Assoc J 1992;147:181-8.

94. Habbick BF, Nanson JL, Snyder RE, Casey RE, Schulman AL. Foetal alcohol syndrome in Saskatchewan: unchanged incidence in a 20-year period. Can J Public Health 1996;87:204-7.

95. May PA, Hymbaugh KJ, Aase JM, Samet JM. Epidemiology of fetal alcohol syndrome among American Indians of the Southwest. Soc Biol 1983;30: $374-87$.
96. Serdula M, Williamson DF, Kendrick JS, Anda RF, Byers T. Trends in alcohol consumption by pregnant women: 1985-1988. JAMA 1991;265:876-9.

97. Sokel RJ, Ager J, Martier S, et al. Significant determinants of susceptibility to alcohol teratogenicity. Ann N Y Acad Sci 1986;477:87-102.

98. Wilsnack SC, Klassen AD, Shur BE, Wilsnack RW. Predicting onset and chronicity of women's problem drinking: a five-year longitudinal analysis. Am J Public Health 1991;81:305-18.

99. Streissguth AP, Clarren SK, Jones KL. Natural history of the fetal alcohol syndrome: a 10-year follow-up of eleven patients. Lancet 1985;2:85-91.

100. Abel EL. Fetal alcohol syndrome in families. Neurotoxicol Teratol 1998;10:85-91.

101. Smith IE, Coles CD. Multilevel intervention for prevention of fetal alcohol syndrome and effects of prenatal alcohol exposure. Recent Dev Alcohol 1991;9:165-80.

102. Smith IE, Lancaster JS, Moss-Wells S, Coles CD, Falek A. Identifying high risk pregnant drinkers: biological and behavioral correlates of continuous heavy drinking during pregnancy. J Stud Alcohol 1987;48:304-9.

103. Haynes G, Dunnagan T, Chistopher S. Determinants of alcohol use in pregnant women at risk for alcohol consumption. Neurotoxicol Teratol 2003; 25:659-66.

104. Greenfield TK, Rehm J, Rogers JD. Effects of depression and social integration on the relationship between alcohol consumption and all-cause mortality. Addiction 2002;97:29-38.

105. Leonardson GR, Loudenburg R. Risk factors for alcohol use during pregnancy in a multistate area. Neurotoxicol Teratol 2003;25:651-8. 